\title{
Tracheobronchial Amyloidosis and Confocal Endomicroscopy
}

\author{
Richard C. Newton ${ }^{a, b}$ Samuel V. Kemp ${ }^{c}$ Guang-Zhong Yang ${ }^{b}$ Ara Darzi ${ }^{a}$ \\ Mary N. Sheppard ${ }^{d}$ Pallav L. Shah ${ }^{c}$ \\ ${ }^{a}$ Department of Surgery and Cancer and ${ }^{b}$ The Hamlyn Centre for Robotic Surgery, Imperial College London, and \\ Departments of ${ }^{\mathrm{c}}$ Respiratory Medicine and ${ }^{\mathrm{d}}$ Histopathology, Royal Brompton Hospital, London, UK
}

\section{Established Facts}

- Tracheobronchial amyloidosis is a rare disease creating circumferential bronchial nodularity and narrowing; it requires typical endobronchial biopsy findings for diagnosis.

- Probe-based confocal endomicroscopy (pCLE) is a cellular resolution optical biopsy technique that may have a role in diagnosing endobronchial malignancy.

\section{Novel Insights}

- In vivo pCLE images of endobronchial amyloid have a 'cotton wool'-like appearance, supporting a potential role for pCLE in the investigation of benign endobronchial diseases such as amyloidosis.

\section{Key Words}

Endobronchial biopsy • Pulmonary amyloidosis •

Confocal endomicroscopy

\section{Abstract}

Tracheobronchial amyloidosis is one of many causes of endobronchial stenosis and nodularity, the concrete diagnosis of which currently requires the finding of apple-green birefringence from endobronchial biopsies. Bronchoscopic probe-based confocal endomicroscopy ( $P C L E$ ) is a novel optical biopsy technique which provides real-time images of the lattice structure of the bronchial basement mem- brane - a finding lost in malignancy. This case study outlines the imperfect, essentially palliative management of this rare disease, and shows for the first time the unusual dappled in vivo pCLE images of amyloid-affected endobronchium.

Copyright $\odot 2011$ S. Karger AG, Basel

\section{Introduction}

Bronchoscopic probe-based confocal endomicroscopy (pCLE) is the product of the recent miniaturisation of the confocal microscope [1]. A $1.4-\mathrm{mm}$ diameter probe is passed down the operating channel of a conventional

\section{KARGER}

Fax +41613061234

E-Mail karger@karger.ch

www.karger.com
(C) 2011 S. Karger AG, Basel

$0025-7931 / 11 / 0822-0209 \$ 38.00 / 0$

Accessible online at: www.karger.com/res
Richard C. Newton

Department of Surgery and Cancer, Imperial College London

St. Mary's Hospital Campus

10th Floor QEQM Building, London W2 1NY (UK)

Tel. +44 798000 5675, E-Mail r.newton@imperial.ac.uk 

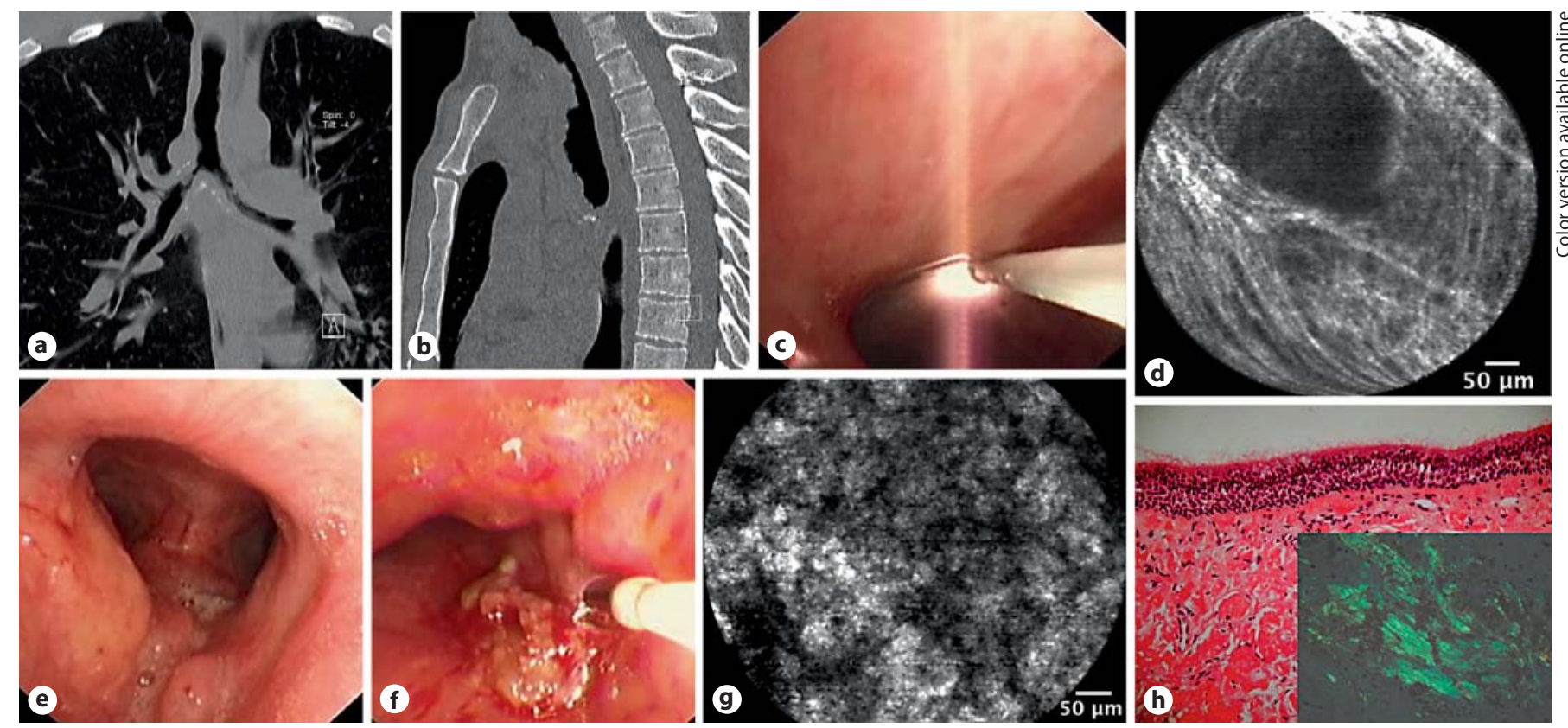

Fig. 1. a, b HRCT demonstrated circumferential endobronchial nodularity and narrowing. Three of 4 macroscopically unaffected areas (c) produced the standard reticular pattern on pCLE imaging (d). Bulky friable plaques narrowed the bronchial tree in many areas, including the lower trachea (e) and right main bronchus (f); pCLE imaging of these areas and one macroscopically normal re-

bronchoscope to fluoresce endogenous fluorophores, such as elastin, with a $488-n m$ laser light. The resulting autofluorescence provides $3.5-\mu \mathrm{m}$ resolution in vivo optical biopsies, showing a reticular pattern of the basement membrane beneath the epithelium of the tracheobronchial tree, which is eliminated by dysplasia or neoplasia [2]. Courtesy of a rare case of primary laryngotracheobronchial amyloidosis, we describe how pCLE may also provide adjunctive images in the diagnosis of benign endobronchial disease.

\section{Case Report}

A 41-year-old black British stonemason developed increasing shortness of breath and dysphonia. He was a current smoker with a 15 pack-year smoking history, but had no previous medical problems. Fixed monophasic wheeze was heard throughout both lung fields, more prominent in the right middle and lower lobes. When a trial of inhaled salbutamol failed to improve his breathing, he was fully investigated. Lung spirometry showed a mixed restrictive and obstructive deficit, an erect chest radiograph showed no abnormalities, and high-resolution computed tomography showed circumferential irregular narrowing and nodularity of the laryngotracheobronchial wall (fig. 1a, b) with some gion produced a 'cotton wool'-like appearance (g). Endobronchial biopsy showed acellular pink material underlying the respiratory epithelium after haemotoxylin and eosin staining (h); viewing this material with polarised light after Congo red staining demonstrated apple-green birefringence (inset). opacity in the left lower and right middle lobes. Flexible bronchoscopy revealed nodular thickening and plaques over the vocal cords and throughout the visible tracheobronchial tree with some mucosal friability (fig. 1e, f). The pCLE probe (Cellvizio ${ }^{\circledR}$ Lung, Mauna Kea Technologies, France) acquired optical biopsies of the mucosa during the bronchoscopy, showing two distinctive patterns: 3 out of 4 macroscopically spared walls produced the fine reticular pattern observed in healthy subjects [2] (fig. 1d); however, 4 out of 5 images acquired from the nodular areas, as well as one macroscopically normal area, showed a fluorescent dappled effect representative of the excrescences caused by the amyloid (fig. $1 \mathrm{~g}$ ).

Endobronchial biopsies of the lesions were fixed and embedded in paraffin, with standard stains showing some squamous metaplasia of the mucosal epithelium overlying extensive amyloid fibrosis containing scattered foreign body-type giant cells. Congo red staining demonstrated extensive amorphous material displaying apple-green birefringence when viewed under highintensity cross-polarised light [3]: the classical histochemical sign of amyloid (fig. 1h). Immunohistochemistry showed binding only of monospecific antibodies to lambda immunoglobulin light chains. Fibreoptic laryngoscopy showed restriction of the right vocal cord from supraglottic laryngeal disease. Serum and urine electrophoresis along with bone marrow biopsy excluded systemic disease, and a serum amyloid P component scintigraph [4] confirmed amyloid confined to the larynx, trachea, bronchi and lungs. 
The patient's voice has strengthened with otorhinolaryngological $\mathrm{CO}_{2}$ laser treatment of the vocal cord foci. There has also been some reduction in dyspnoea from endobronchial balloon dilatation, with subsequent debulking initially using cryotherapy and then an argon plasma laser.

\section{Discussion}

Amyloidosis represents a spectrum of diseases which feature abnormal deposition of randomly orientated insoluble extracellular fibrillar proteins. Whilst more commonly a systemic condition (primary or secondary), localised amyloidosis is restricted to a single organ such as the bladder, skin, heart or respiratory tract. Respiratory amyloidosis, first described in 1877 [5], is described as diffuse parenchymal (the worst prognosis), nodular parenchymal (often an incidental finding) [6] or, as in this patient, (laryngo)tracheobronchial amyloidosis [7]. Unlike in tracheobronchopathia osteochondroplastica, the lesions do not spare the posterior wall. Presumptive diagnoses of asthma or chronic bronchitis often precede de- finitive diagnosis from bronchoscopy and endobronchial biopsy. Screening for fibrillar-type and systemic disease should follow [8]. In terms of therapy, pharmacological prevention of deposition remains an aspiration [9], whereas symptomatic treatment includes debulking using the methods in this case, along with stenting and external beam radiation [10].

The amyloid material appears to be fluorescent with 488-nm pCLE. A previous paper demonstrated innate fluorescence of the macroscopically abnormal amyloid plaques during autofluorescence bronchoscopy with blue light [11]. The pCLE images have a patchy 'cotton wool'like appearance due to the accumulation of the autofluorescent amyloid material in the mucosa and submucosa. The normal reticular pattern from the elastin component of the lamina densa and lamina reticularis [2] is disrupted. As this appearance was also observed in a macroscopically normal region, confocal endomicroscopy may have a role in identifying early-stage tracheobronchial amyloidosis, as well as affected areas that are macroscopically normal under white light imaging.

\section{References}

1 Newton RC, Kemp SV, Shah PL, Elson D, Darzi A, Shibuya K, Mulgrew S, Yang GZ: Progress toward optical biopsy: bringing the microscope to the patient. Lung 2011, Feb 20 [Epub ahead of print].

2 Thiberville L, Moreno-Swirc S, Vercauteren T, Peltier E, Cave C, Bourg Heckly G: In vivo imaging of the bronchial wall microstructure using fibered confocal fluorescence microscopy. Am J Respir Crit Care Med 2007; 175:22-31.

3 Puchtler H, Sweat F, Levine M: On the binding of Congo red by amyloid. J Histochem Cytochem 1962;10:355-364.

4 Hawkins PN, Lavender JP, Pepys MB: Evaluation of systemic amyloidosis by scintigraphy with 123I-labeled serum amyloid P component. N Engl J Med 1990;323:508-513.
5 Lesser A: Ein Fall von Enchondroma osteiodes mixtum der Lunge mit partieller amyloid Entortung. Virchows Arch (Path Anat) 1877;69:404-408.

6 Cottin V, Cordier JF: Interstitial pulmonary amyloidosis. Respiration 2008;75:210.

7 O'Regan A, Fenlon HM, Beamis JF Jr, Steele MP, Skinner M, Berk JL: Tracheobronchial amyloidosis. The Boston University experience from 1984 to 1999. Medicine (Baltimore) 2000;79:69-79.

8 Shah PL, Gillmore JD, Copley SJ, Collins JV, Wells AU, du Bois RM, Hawkins PN, Nicholson AG: The importance of complete screening for amyloid fibril type and systemic disease in patients with amyloidosis in the respiratory tract. Sarcoidosis Vasc Diffuse Lung Dis 2002;19:134-142.
9 Pepys MB, Herbert J, Hutchinson WL, Tennent GA, Lachmann HJ, Gallimore JR, Lovat LB, Bartfai T, Alanine A, Hertel C, Hoffmann T, Jakob-Roetne R, Norcross RD, Kemp JA, Yamamura K, Suzuki M, Taylor GW, Murray S, Thompson D, Purvis A, Kolstoe S, Wood SP, Hawkins PN: Targeted pharmacological depletion of serum amyloid P component for treatment of human amyloidosis. Nature 2002;417:254-259.

10 Kalra S, Utz JP, Edell ES, Foote RL: Externalbeam radiation therapy in the treatment of diffuse tracheobronchial amyloidosis. Mayo Clin Proc 2001;76:853-856.

11 De Keukeleire T, Hanon S, Dieriks B, Vanmaele L, Noppen M: Tracheobronchial amyloidosis: a bright sight with autofluorescence light. Respiration 2009;77:454. 